\title{
Review
}

\section{Regulation of Natural Health Products in Canada}

\author{
Yoshinori Mine and Denise Young
}

Department of Food Science, University of Guelph, Guelph, Ontario, Canada N1G 2W1

Received May 6, 2009; Accepted May 7, 2009

In Canada, there has been an increasing presence of and interest in natural health products (NHPs). While some of these products are deeply immersed in cultural heritage and have been used for decades, questions have emerged regarding the effectiveness, safety, and quality of these and other non-traditional NHPs. Some NHPs can cause adverse reactions when taken with other NHPs, prescription drugs, and even food; while others have been adulterated with contaminants. At the same time, Canadians are interested in health and wellness and are taking an active role in choosing products that may have a direct impact on their health. The Canadian government responded on January 1, 2004 by legislating the Natural Health Products Regulations (NHPR), whose main goal is to maintain the safety, efficacy, and quality of NHPs while allowing consumers to make an informed choice. The NHPR govern the sale, manufacture, packaging, labeling, importation, distribution and storage of NHPs; and provide regulations concerning licensing, good manufacturing practices, clinical trials, adverse reactions and health claims. The introduction of the NHPR is an innovative approach to regulating NHPs, but numerous challenges have emerged since its promulgation: processing backlogs of product licenses; classification and/or clarification of NHPs in food formats, of naturally-sourced prescription drugs, and of human-use antiseptic drugs; and knowledge dissemination of the safety hazards associated with non-licensed NHPs and previously licensed NHPs. This review outlines the regulation of NHPs in Canada and highlights some of the challenges and subsequent measures implemented to handle these issues.

Keywords: natural health products, regulation, health claims, safety, functional foods

\section{Introduction}

Natural health products (NHPs) such as traditional Chinese medicine, homeopathic remedies, and herbal remedies are used by many around the world and are a popular form of alternative medicine therapy. With Canada's cultural diversity and open-minded nature, it is not surprising to find that $71 \%$ of Canadians have used a natural health product at least once and $38 \%$ of those do so daily (Health Canada 2005). NHPs are often perceived to be safe due to their natural origin; however they are pharmacologically active and can interact with other NHPs, prescription medicines, and foods (Brulotte and Vohra 2008, Singh and Levine 2007) causing adverse effects. There are potential NHP-associated interactions among children (Goldman et al., 2008, Seely et al., 2007), adults (Laliberté et al., 2007), and seniors (Putnam et

*To whom correspondence should be addressed. E-mail: ymine@uoguelph.ca al., 2006) taking medication for a range of illnesses including cancer, osteoarthritis, and renal insufficiency. Adverse effects can also be caused by NHP contamination, adulteration, or misuse. Therefore there is a need to ensure the safety, efficacy and quality of NHPs, while at the same time providing consumers with the knowledge and confidence to make informed choices. The majority of Canadians agree that NHPs can be used to maintain or promote health or treat illness, but nine in ten agree that all NHP manufacturers must ensure that the products they sell to consumers are safe and that the Government of Canada should regulate the claims made by NHP manufacturers (Health Canada 2005).

The purpose of this review is to provide an overview of the regulation of natural health products in Canada, significant developments since regulatory implementation, and future perspectives that have resulted from some of the challenges along the way. 


\section{Definition of Natural Health Products (NHPs)}

Health Canada defines natural health products as vitamin and mineral supplements, herbal and plant-based remedies, homeopathic medicines, traditional medicines (such as traditional Chinese medicines), probiotics, and other products such as amino acids, and omega and essential fatty acids (Health Canada 2003a). They specifically exclude biologics, substances regulated under the Tobacco Act, controlled substances, prescription medications, and products administered by injection. NHPs must possess a certain level of safety to be sold as over-the-counter products. They can be present in items such as certain toothpastes, antiperspirants, shampoos, facial products and mouthwashes due to their medicinal ingredients and intended uses. They are marketed and used to prevent or treat an ailment or condition, to reduce a health risk, or to maintain good health.

\section{Legislation}

As early as 1997, Canadians began pressuring the government about the regulation and accessibility of herbal remedies. Advisory panels on natural health products, public reviews, and consultations with health care providers, industry, consumer groups, and herbalists led to recommendations on a distinct regulatory framework for natural health products. After consideration and approval from the House of Commons, the Natural Health Products Directorate (NHPD, previously known as the Office of Natural Health Products) was created to ensure the safety of these products, while allowing access to a full range of health products. Numerous consultations between NHPD and interested parties/stakeholders between 1999 and 2003 led to a final version of the Natural Health Products Regulations (NHPR) published in the Canada Gazette (Health Canada 2003a). The Regulations came into force on January 1, 2004, with a transitional period of 2 to 6 years. The establishment of the NHPR oversees over 40,000 supplements and traditional and alternative medicines sold in Canada and its main goal is to provide Canadians the assurance that NHPs sold in Canada are safe, effective, and of high quality. As a result, NHPR govern the sale, manufacture, packaging, labeling, importation, distribution and storage of NHPs.

\section{Product Licensing}

During NHPR's 6-year transition period, NHPs will be issued product licenses pending a successful review of a Product License Application (PLA) submitted by the manufacturer, distributor, packager, labeler or importer of the product (Health Canada 2003b). NHPs are sorted accorded to perceived risk, and compliance deadlines are set accordingly. Higher risk products are given a higher priority compliance deadline for submission of a PLA. However, products that already have an associated DIN, and as a result of this have already been assessed for safety and quality, are deemed to be of the lowest risk and have the maximum 6 years to be licensed.

A PLA must be submitted to the NHPD for a pre-market review prior to the issuing of a product license. The PLA must include information on the safety, efficacy and quality of the NHP, such as medicinal ingredients, source, potency, non-medicinal ingredients, and recommended uses, as well as any proposed labeling information. The extensiveness of the PLA depends on the NHP and/or its ingredients (Health Canada 2004c).

Currently, compendial PLAs (can be traditional, nontraditional, or homeopathic applications) which have ingredients already compiled in NHPD's Compendium of Monographs (Health Canada 2007a) do not require any further supporting safety and efficacy information. The same holds true for homeopathic DIN, transitional DIN, and Therapeutic Products Directorate (TPD) Category IV-type applications that have previously issued DINs (Health Canada 2006a). Non-compendial PLAs, including both traditional use and non-traditional use claims, will be reviewed in great detail (Health Canada 2006h).

In March 2009, Health Canada introduced The New RiskBased Approach (RBA) for Natural Health Products, which outlines proposed modifications to product and site licensing (Health Canada 2009c). The RBA was developed in response to a regulatory review where stakeholders felt that NHPs should be regulated proportionally to their risk level and that the regulatory requirements were too onerous for this product type, given the low risk nature of these products and their history of safe use (Health Canada 2008c). The RBA envisions two classes of product licenses, which depend on the degree of certainty associated with a product's safety, quality or health claims as shown in Table 1. Abbreviated labeling standards are also being developed for for a limited set of efficacy/health claims for certain products within the "Class I" category.

Once a PLA is approved, the product is now authorized for sale in Canada and the NHP is issued a Natural Product Number with the prefix NPN or a homeopathic medicine number starting with DIN-HM, either of which must be displayed on the product's label. At this point, the licensee is required to keep records pertaining to ingredient listing and any information that would be necessary for a lot or batch recall for a minimum of one year beyond the NHP expiry date.

There has been an overwhelming backlog of PLAs to be processed since the introduction of the NHPR; however, a recent progress report (Health Canada 2009e) stated that over 
Table 1. Classes of product licenses proposed under the Risk-Based Approach for Natural Health Products.

\begin{tabular}{|c|c|c|}
\hline Class & Description & Assessment \\
\hline Class I & $\begin{array}{l}\text { Products and/or claims for which there are readily } \\
\text { available, authoritative and high-quality sources } \\
\text { of evidence (called } \\
\text { Pre-Cleared Information) relating to their efficacy, } \\
\text { safety and quality. } \\
\text { Pre-Cleared Information includes: } \\
\text { widely recognized reference sources, such as } \\
\text { pharmacopeias, monographs and labeling } \\
\text { standards } \\
\text { expert opinion reports } \\
\text { international standards } \\
\text { information from other regulatory bodies, such } \\
\text { as market authorization/licensing decisions, } \\
\text { and }\end{array}$ & Minimal \\
\hline Class II & $\begin{array}{l}\text { Products and/or claims considered a higher risk } \\
\text { due to lack of existing evidence (e.g. a novel prod- } \\
\text { uct) }\end{array}$ & $\begin{array}{l}\text { A thorough assessment of } \\
\text { safety, efficacy and quality }\end{array}$ \\
\hline
\end{tabular}

$60 \%$ of PLAs have been completed, with over 10,000 NHPs issued product licenses. This was achieved by fast-tracking certain types of lower-risk NHP reviews and new product monographs, and grouping applications for similar product types. Health Canada also launched the Natural Health Products Online Solution, an electronic system aimed at processing license applications for product, site, and clinical trial authorizations for NHPs (Health Canada 2009d). Since many product applications in the past held lengthy processing times because they contained only partially complete information, the new electronic product license application form guides the applicant through the process of completing the required information and provides immediate feedback on missing or inappropriate information, and as such, supports the new approach to compendial reviews (Health Canada 2008g) whereby PLAs must correspond in full to the monograph in order to be licensed.

The form also allows applicants to pick from a list of preapproved substances to ensure accuracy and facilitate a rapid completion and submission of the form. An online database listing all Canadian approved NHPs has also recently been introduced (Health Canada 2008f). These initiatives are part of the S.T.E.P.S (Standardized Claims for NHPs and PreCleared Information; Transparency and Openness; Electronic Solutions; Process Improvements; Service Delivery) plan for addressing the current NHP license application backlog (Health Canada 2009f). Training workshops with stakeholders to facilitate understanding of the NHPR, and education and awareness efforts targeted towards NHP consumers are also part of the S.T.E.P.S plan. Education and awareness are key focus areas since, apart from consulting doctors and NHP practitioners, consumers are increasingly turning to the internet (Whelan et al., 2009) and pharmacists (Kwan et al., 2008) for advice. The S.T.E.P.S program may also help in the retention of smaller NHP industry firms who may have felt marginalized due to limited resources during the implementation of the regulatory standards (Laeeque et al., 2006).

For PLAs that were not approved and thus not granted product licenses, Health Canada implemented a process, called the Reconsideration Process for Natural Health Products (Health Canada 2008h), by which companies can formally ask for reconsideration for any of these decisions. This guidance document outlines the formal procedures, 
documentation, and deadlines to follow when requesting the NHPD to reconsider a decision to refuse to issue or amend a product or site license.

\section{Site Licensing}

All manufacturers, packagers, labelers, and importers are required to have NHPD approved site licenses, obtained through the submission of a site license application (SLA). For NHPs that are manufactured, packaged, and labeled outside of Canada, the Canadian importer must hold a site license and account for all foreign site activities in its license (Health Canada 2007b)

Sites are required to have distribution records, product recall procedures, handling, storage and product delivery procedures (if applicable) and meet good manufacturing practice requirements (GMPs). GMP requirements provide a certain degree of safety and quality; however, currently GMP compliance is reviewed only through the submission of a Quality Assurance Report (QAR) form, with the form being updated periodically during the renewal of the site license. Expiry dates for site licenses range from yearly, to every 2 years, and to every 3 years as the length of time of holding a site license increases. NHP manufacturers, packagers, labelers, and importers were given a transition period of 2 years after the promulgation of the NHP Regulations to obtain a site license.

\section{Good Manufacturing Practices (GMP)}

GMP requirements are outlined in the Good Manufacturing Practices Guidance Document (Health Canada 2006e). GMPs ensure that: premises and equipment are appropriate for production of the NHP; site personnel have suitable education, qualifications and training; appropriate sanitation, health and hygiene programs are implemented; standard operating procedures are followed; products meet their specifications and are stable; proper sample retention and recordkeeping programs are met; and recall reporting procedures are in place. GMP implementation should complement "inhouse" quality systems already carried out by the licensee. Currently, there is no on-site evaluation of GMP compliance before or after a site license is issued, unless there is a postmarket compliance issue. The RBA is proposing the inclusion of an on-site GMP compliance verification as part of the site license assessment process. This would help in the identification of risks and potential non-compliance issues prior to the NHP entering the market.

\section{Adverse Reaction Reporting}

Product licensees are responsible for implementing and maintaining a system for reporting adverse reactions (AR) associated with their NHPs (Health Canada 2004a). Case reports must be submitted to Health Canada for serious ARs through the Adverse Reaction Reporting Form Template, and annual and interim summary reports must include all ARs reported. Annual and interim reports must include a concise and critical analysis of the ARs reported and whether any significant safety issues have been identified with their use. Any additional AR information from new studies, such as clinical trials, must also be monitored and reported. These self-regulated measures ensure quality and traceability in the event products are required to be quarantined or recalled, and assists Health Canada in issuing warnings and advisories (when appropriate) to the public. Any individual having experienced an adverse reaction to a NHP can also report this to the Marketed Health Products Directorate (MHPD), which oversees post-approval safety surveillance, assessment of signals and safety trends and risk communications concerning all regulated marketed health products (Health Canada 2004b).

\section{Clinical Trials}

In some product license applications, the effect of the NHP on human subjects may not have been investigated. In these cases, a clinical trial may be recommended to discover or verify the product's clinical, pharmacological or pharmacodynamic effects; to identify any adverse reactions related to its use; to study its absorption, distribution, metabolism, or excretion; or to ascertain its safety or efficacy. A clinical trial application (CTA) must be submitted to and approved by the NHPD prior to the start of the trial. The NHPR outlines provisions for clinical trials conducted with NHPs, including principles of good clinical practice (GCP), roles and responsibilities of sponsors, and requirements for protocols, product labeling, record keeping, adverse event reporting, site information, trial application packages, and research ethics board approval. Further information on conducting a NHP-based clinical trial can be found in the Clinical Trials for Natural Health Products Guidance Document (Health Canada 2006b). It is worth noting that a clinical trial may not always be necessary in a PLA since the NHPD allows for a range of evidence to be submitted to support the NHP's safety, efficacy, and quality. If clinical trials are used and referenced, however, the quality of the trial, and as a result the data gained from the trial, must be of high regard (Foster et al., 2005, Whelan et al., 2008).

\section{Labeling and Packaging}

Labeling and packaging requirements for all NHPs are outlined in the NHPR (Health Canada 2006f) and are established to ensure consumers can make informed choices. The 
required label information includes product name, quantity, and ingredient listing (both medicinal and non-medicinal); recommended conditions of use (i.e. recommended use or purpose, dosage form, route of administration, recommended dose, and any cautionary statements, warnings, contraindications and possible adverse reactions associated with the product); product traceability information such as lot number, expiry date, name and address of product licensee and importer, if applicable; and any special storage conditions. The NHP must be packaged in secure, tamper-proof packages and the label must indicate the product's security feature if this is not obvious in the packaging.

\section{Health Claims}

The NHPD defines a health claim as 'a statement that indicates the intended beneficial effect of an NHP when used in accordance with the recommended conditions of use' (Health Canada 2006h). There are currently 3 types of NHP health claims: treatment claims, risk reduction claims and structure/ function claims, as described in Table 2. Within these types of claims are 2 categories of claims, as described in Table 3, with varying degrees of supportive evidence (Health Canada 2006d). As previously mentioned, abbreviated labeling standards for generalized health claims are being developed under the RBA. These generalized health claims refer to health claims for lower-risk NHPs and would facilitate the licensing of certain types of NHPs (Health Canada 2009c). These labeling standards would help NHP product license applicants provide truthful and accurate claims based on available evidence. An abbreviated labeling standard for a generalized health claim would consist of:

- An approved claim statement (e.g. "Used in Aromatherapy as a sleep aid");

- Pre-approved reference material which contains supporting evidence for the generalized claim;

- Ingredients to which the claim would apply, and

- Relevant dosage and risk information

A new assessment stream for the licensing of homeopathic medicines (HM) with non-specific recommended uses or purposes was announced in April 2008 (Health Canada 2008e). Applicants for HM with non-specific health claims will be eligible for expedited review by attesting to a HM Labeling Standard which bears similarity to a monograph.

\section{Safety Issues}

In a recent Ipsos-Reid survey commissioned by Health Canada, one half of Canadians surveyed believed natural health products to be safe because they are made using natural ingredients (Health Canada 2005). The main goal of the NHPD, as outlined in the NHPR, is to provide Canadians with informed choices on NHPs, while at the same time maintaining safety, efficacy and quality. However, the infor-

Table 2. Types, descriptions, and examples of current NHP health claims.

\begin{tabular}{cll}
\hline NHP Claim type & \multicolumn{1}{c}{ Description } & Example \\
\hline Therapeutic & $\begin{array}{l}\text { Relates to the diagnosis, treatment and } \\
\text { mitigation or prevention of a disease, disorder } \\
\text { or abnormal physical state or its symptoms in } \\
\text { humans }\end{array}$ & $\begin{array}{l}\text { "Effective in reducing joint } \\
\text { pain" }\end{array}$ \\
\hline Risk reduction & $\begin{array}{l}\text { Based on the relationship between a medicinal } \\
\text { ingredient and the reduction in the risk of } \\
\text { developing a certain disease, possibly by the } \\
\text { alteration of a major risk factor or other } \\
\text { contributing factor involved in the development } \\
\text { of disease }\end{array}$ & $\begin{array}{l}\text { "Use of [product xyz] is } \\
\text { risk of osteoporosis" }\end{array}$ \\
\hline Structure / Function & $\begin{array}{l}\text { Relates to the effect or support of an NHP } \\
\text { ingredient on the structure or anatomical, } \\
\text { physiological or mental function in the human } \\
\text { body }\end{array}$ & "Maintains healthy gums" \\
\hline
\end{tabular}


Table 3. Description and evidence of efficacy required for traditional and non-traditional use claims.

\begin{tabular}{|c|c|c|}
\hline Claim category & Description & Evidence of efficacy \\
\hline Therapeutic & $\begin{array}{l}\text { Refers to the practices, based on the experience } \\
\text { of indigenous or different cultures, used in the } \\
\text { maintenance of health or the prevention, diagno- } \\
\text { sis or treatment of physical and/or mental illness } \\
\text { for at least } 50 \text { consecutive years }\end{array}$ & At least 2 independent references \\
\hline Non-traditional use & $\begin{array}{l}\text { Use which does not conform to the description } \\
\text { of "Traditional use" as described above }\end{array}$ & $\begin{array}{l}\text { Supported by a variety of scientific } \\
\text { evidence ranging from highest to } \\
\text { lowest strength: } \\
\text { I. Randomized controlled clinical } \\
\text { trials } \\
\text { II. Non-randomized and non-control } \\
\text { clinical trials } \\
\text { III. Descriptive and observational } \\
\text { studies } \\
\text { IV. Expert opinion reports, published } \\
\text { articles (peer-reviewed), conclu- } \\
\text { sions of other reputable regulatory } \\
\text { agencies, and previous marketing } \\
\text { experience } \\
\text { V. References to traditional uses }\end{array}$ \\
\hline
\end{tabular}

mation required as proof of safety can be a contentious issue. For common constituents of NHPs, such as certain amino acids, herbs, vitamins and minerals, safety can be inferred by its reference to the NHP's compendium of monographed materials. Safety may be based on historical use of the substance, or its chemically analogous counterparts whereby the conditions of use is similar to that intended. Toxicological animal studies, as well as statistically valid human clinical trials, can also be used to support safety requirements.

Dosage must be considered as a safety parameter since too much of any substance may result in adverse effects. The nature of the adverse effect may be useful in identifying the mechanism of toxicity and can lead to the recognition of population sub-groups who may be at greater risk for these effects (Nestmann et al., 2006). The recommended dose, as stated on the NHP label, is based on its conferred physiological or nutritional effect (which may be declared on its health claim) and is at a safe level for use. If the dosage required for efficacy compromises safety, it will not be approved under NHP regulations.
Once a product has undergone all regulatory safety evaluations and is available for sale on the market, the NHPD relies on AR reports submitted by the NHP licensee or consumers and new scientific information for the ongoing tracking of safety. If previously approved NHP ingredients are found to pose a risk to human health, Health Canada can issue advisories against their use. One such advisory was issued for the relabeling of over-the-counter cough and cold medicines for children under the age of 6 years (Health Canada 2008d).

A Health Canada review and input from a Scientific Advisory Panel found that although cough and cold medicines have a long history of use in children, there was limited evidence supporting its effectiveness in children. More importantly, reports of misuse, overdose and rare but serious potential side effects (including convulsions, increased heart rate, decreased level of consciousness, abnormal heart rhythms and hallucinations) have raised concerns about its use in children under the age of 6 years. Health Canada is requiring manufacturers of over-the-counter cough and cold medicines (such as antihistamines, antitussives, expectorants, 
and decongestants), which contain specific active NHP ingredients, to relabel these products by fall 2009 and indicate that these medicines should not be used in children under 6 years of age.

Two other Health Canada advisories concerning black cohosh and L-arginine have been extensively reviewed by Martyres et al. (2008). There have also been ongoing product-specific advisories and health alerts issued by Health Canada against the use of unapproved foreign products, illegally present in the market, which may have unapproved health claims (such as citing the treatment of serious disease), and/or which may contain undeclared prescription drugs or high levels of contaminants such as toxins and human placenta. Many of these products have no declared sideeffects or health risks associated with their consumption and pose a continual challenge to NHPD and Health Canada in keeping abreast of all new products being introduced to the marketplace.

\section{NHPs in Canada}

NHPs that have been licensed for sale in Canada are labeled with a NPN or a DIN-HM followed by an eightdigit number (Health Canada 2006g). All licensed NHPs are available in the Licensed Natural Health Products Database (LNHPD; Health Canada, 2008f). The LNHPD provides information on the licensed NHP name, licensee, NPN or DIN-HM, the product's medicinal and non-medicinal ingredients, dosage, health claim or indication, and any risk information associated with the product's use. As the NHP definition is wide ranging, a random search of "toothpaste" on the LNHPD produced over 50 results with many brand name products containing NHP-regulated medicinal ingredients such as strontium chloride, sodium fluoride, potassium nitrate, and sodium fluoride. On the database, vitamins are present as solid or chewable capsules, in single or in combination capsules, and even in non-traditional forms such as chewable bears. NHPs for cold medicines contain a variety of medicinal ingredients such as Panax quinquefolius L, Andrographis paniculata, Echinacea angustifolia, Echinacea purpurea, N-acetyl-L-cysteine, and Vitamin C.

\section{Marketing}

Any health claim approved by the NHPD can be indicated on the NHP product label and marketed to consumers. According to the Food and Drug Act, 'no drug, food, cosmetic or device may be represented as a treatment, preventative or cure for any of the diseases, disorders or abnormal physical states listed on Schedule A' (Department of Justice 2009). Schedule A lists over 40 serious diseases such as arthritis, cancer, diabetes, hypertension and obesity. This stipulation of the Act, however, is at odds with the health claims permitted on some NHPs. Before the NHPR came into force, the prohibition of Schedule A-related claims was to prevent advertising and labeling fraud, and to prohibit the sale and advertising of products intended for the self-care of serious diseases and for the treatment of conditions where no treatment was known to medical science. In other words, the public was encouraged to seek the advice of a medical practitioner if they had any Schedule A diseases. As of June 1, 2008, NHPs and nonprescription drugs under the FDA were permitted to label and advertise approved preventative claims for the diseases listed in Schedule A, provided that only the exact wording approved by Health Canada is used for labeling and advertising (Health Canada 2008a). This regulatory amendment to exempt NHPs and nonprescription drugs under the FDA from the Section 3 preventative prohibition for Schedule A diseases does not include prescription drugs, with the exception of veterinary-use drugs (so long as the drug is in a form not suitable for human use or is labeled for veterinary use only), and controlled drugs. Food, medical devices, and cosmetics also continue to be prohibited from carrying preventative claims in labeling and advertising to the general public for diseases remaining in Schedule A (unless otherwise permitted in other provisions in the FDA or its regulations).

Health Canada has provided consumer advertising guidelines for NHPs to help advertisers develop advertising messages that meet the provisions of the FDR, the NHPR, and other related Health Canada Policies and Guidelines (Health Canada 2006c). Even before an advertisement is allowed to be publicly revealed, advertisers must submit for review an advertising copy to a pre-clearance agency which has publicly attested to meeting the attestation criteria established by Health Canada.

\section{Future perspectives}

NHPs in Food Formats Since the promulgation of the NHPR, Health Canada has received several hundred PLAs for products in food formats that have characteristics of both NHPs and foods. PLAs have been submitted for NHPs in juices, drinks, cakes, yogurts, and butters. This has posed a regulatory challenge since they could be classified under the NHPR or the FDR. The availability of NHPs in food formats has raised concerns within Health Canada that these products may be confusing to the public and industry since consumers usually consume foods freely without considering its recommended conditions of use and potential risks as conferred by these food-like NHPs. Health Canada is exploring a regulatory amendment to place food-like NHPs under an appropriate regime, but until then it has issued a new guidance 
document, Classification of Products at the Food-Natural Health Product Interface: Product in Food Formats (Health Canada 2009b), to help clarify which products most appropriately fall under the NHPR versus the FDR. Classification of products is based on product composition, representations, format, public perception and history of use. If products are classified as foods, they are subject to the FDR and regulatory compliance and enforcement action is carried out by the Canadian Food Inspection Agency. If products are considered NHPs, they are subject to the NHPR and compliance and enforcement actions would be undertaken by the Health Products and Food Branch Inspectorate (HPFBI). Health Canada is also developing a series of questions and answers, a glossary of terms, and a template to help industry apply criteria from this guidance document. A workshop/brainstorming session with industry and consumer stakeholders is also planned to discuss risk mitigation strategies for NHPs in food formats.

Schedule F of the Food and Drug Regulations Schedule $\mathrm{F}$ of the FDR lists a wide variety of ingredients that require the issuing of a prescription for use. It was recognized that some of these ingredients are naturally sourced and may now fall under the NHP umbrella. In order to modify or remove a Schedule F substance, the ingredients need to undergo a scientific review by the NHPD and the Therapeutic Products Directorate (TPD), whereby factors such as toxicity, pharmacological properties and therapeutic uses are considered. As of March 2009, the following 11 naturally-sourced medicinal ingredients found in Schedule F of the FDR are undergoing scientific review: apiol, centella asiatica, deanol, dimethyl sulfoxide, dopamine, gold, levocarnitine, lovastatin, theobromine, L-tryptophan, and uracil (Health Canada 2009a). Once an ingredient is not listed on Schedule F it may be sold as a non-prescription drug under the FDR or as an NHP under the NHPR and may be available (under certain conditions) for use as or in over-the-counter NHPs.

Human-Use Antiseptic Drugs The Food and Drugs Act states that any substance that is used for the "mitigation or prevention of disease" is a drug and that a drug must not be labeled "in a manner that is false, misleading or deceptive or is likely to create an erroneous impression" (Department of Justice Canada 2009). An antiseptic product is one that prevents or arrests the growth of microorganisms. Currently antiseptic products are regulated as pharmaceutical drugs or NHPs. Manufacturers of antiseptic products for human use have proposed labeling that makes the implicit or explicit claim of "mitigation or prevention of disease" which would automatically categorize them as drugs in accordance with the Act. The use of such a claim needs to be validated through the evaluation of supporting scientific evidence or by confirming conformance to a prescribed and acceptable standard. A standard does exist for certain personal domestic use antiseptics in the Monograph for Antiseptic Skin Cleansers; however, not all antiseptic products are covered in this monograph. As such, there has been confusion amongst industry during the drug submission process. The HumanUse Antiseptic Drugs Guidance Document was released for stakeholder consultation (Health Canada 2008b) and outlines the categories of antiseptic products, the filing process for antiseptic submissions, required documentation, and detailed data recommendations for specific claims. This was aimed to provide clarity and direction for human-use antiseptic drug applications.

\section{Conclusion}

The regulation of natural health products in Canada is a major step for providing Canadians with access to safe, effective, and high quality NHPs. Although there have been many clinical and regulatory challenges, Health Canada maintains a transparent and open dialogue with stakeholders to ensure their proposed decisions are met with cooperation. As the number of NHP users increases and the range of unauthorized NHPs in the market widens, assessing safety and communicating risk to all consumers become critical. Canada's NHP regulations are relatively young and many learning experiences are anticipated as the NHP sector grows.

\section{References}

Brulotte J. and Vohra S. (2008). Epidemiology of NHP-Drug Interactions: Identification and Evaluation. Curr. Drug Metab., 9(10), 1049-54.

Department of Justice Canada (2009). Food and Drugs Act. http:// laws.justice.gc.ca/en/showtdm/cs/F-27

Foster B.C., Arnason J.T. and Briggs C.J. (2005). Natural health products and drug disposition. Annu. Rev. Pharmacol. Toxicol., 45, 203-26.

Goldman R.D., Rogovik A.L., Lai D., Vohra S. (2008). Potential interactions of drug-natural health products and natural health products-natural health products among children. J. Pediatr, 152(4):521-6.

Health Canada (2003a). Natural Health Products Regulations. http:// gazette.gc.ca/archives/p2/2003/2003-06-18/html/sor-dors196eng.html

Health Canada (2003b). Transition Guidance Document for Natural Health Products. http://www.hc-sc.gc.ca/dhp-mps/prodnatur/legislation/docs/transition_guide_doc-eng.php

Health Canada (2004a). Adverse Reaction Reporting. http://www. hc-sc.gc.ca/dhp-mps/prodnatur/legislation/docs/arr-dri-eng.php

Health Canada (2004b). Adverse Reaction Reporting for Health Care Providers and Consumers. http://www.hc-sc.gc.ca/dhp-mps/ 
prodnatur/legislation/docs/arr-dri_hcpc-fscc-eng.php

Health Canada (2004c). Overview of the Natural health Products Regulations Guidance Document. http://www.hc-sc.gc.ca/dhp$\mathrm{mps} /$ prodnatur/legislation/docs/regula-regle_over-apercu-eng.php

Health Canada (2005). Baseline Natural Health Products Survey

Among Consumers. http://www.hc-sc.gc.ca/dhp-mps/pubs/natur/ eng_cons_survey-eng.php

Health Canada (2006a). A Summary of NHP/DRUG Classification of TPD Category IV Labelling Standards Ingredients. http://www. hc-sc.gc.ca/dhp-mps/prodnatur/applications/licen-prod/monograph/list_mono4-eng.php

Health Canada (2006b). Clinical Trials for Natural Health Products. http://www.hc-sc.gc.ca/dhp-mps/prodnatur/legislation/docs/ clini_trials-essais_nhp-psn-eng.php

Health Canada (2006c). Consumer Advertising Guidelines for Marketed Health Products (for Nonprescription Drugs including Natural Health Products Guidance Document. http://www.hc-sc. gc.ca/dhp-mps/advert-publicit/pol/guide-ldir_consom_consumeng.php

Health Canada (2006d). Evidence for Safety and Efficacy of Finished Natural Health Products. http://www.hc-sc.gc.ca/dhp-mps/ prodnatur/legislation/docs/efe-paie-eng.php

Health Canada (2006e). Good Manufacturing Practices Guidance Document. http://www.hc-sc.gc.ca/dhp-mps/prodnatur/legislation/docs/gmp-bpf-eng.php

Health Canada (2006f). Labelling Guidance Document. http://www. hc-sc.gc.ca/dhp-mps/prodnatur/legislation/docs/labelling-etiquetage-eng.php

Health Canada (2006g). Natural Health Products Compliance Guide. http://www.hc-sc.gc.ca/dhp-mps/prodnatur/legislation/ docs/complian-conform_guide-eng.php

Health Canada (2006h). Natural Health Products Directorate Guidance Document. http://www.hc-sc.gc.ca/dhp-mps/prodnatur/legislation/docs/license-licence_guide_tc-tm-eng.php

Health Canada (2007a). Compendium of Monographs. http://www. hc-sc.gc.ca/dhp-mps/prodnatur/legislation/docs/compendiumeng.php

Health Canada (2007b). Site Licensing Guidance Document. http:// www.hc-sc.gc.ca/dhp-mps/prodnatur/legislation/docs/slgd-drleeng.php

Health Canada (2008a). Consultation - Draft Guidance Document -Schedule A and Section 3 to the Food and Drug Acts. http://www. hc-sc.gc.ca/dhp-mps/consultation/drug-medic/scheda-eng.php

Health Canada (2008b). Draft Guidance Document - Human-Use Antiseptic Drugs. http://www.hc-sc.gc.ca/dhp-mps/consultation/ drug-medic/antiseptic-eng.php

Health Canada (2008c). Final Report - Online Consultation: Natural Health Product Regulatory Review. http://www.hc-sc.gc.ca/dhpmps/pubs/natur/nhprr-erpsn-final-eng.php

Health Canada (2008d). Health Canada Releases Decision on the
Labeling of Cough and Cold Products for Children. http://www. hc-sc.gc.ca/ahc-asc/media/advisories-avis/_2008/2008_184-eng. php

Health Canada (2008e). Important Notice - New Assessment Stream for the Licensing of Homeopathic Medicines with Non-Specific Recommended Uses or Purposes. http://www.hc-sc.gc.ca/dhp$\mathrm{mps} /$ prodnatur/legislation/docs/new_hm_stream-nouv_volet-eng. php

Health Canada (2008f). Licensed Natural Health Products Database. http://www.hc-sc.gc.ca/dhp-mps/prodnatur/applications/licenprod/lnhpd-bdpsnh-eng.php

Health Canada (2008g). New Approach to Compendial Reviews. http://www.hc-sc.gc.ca/dhp-mps/prodnatur/bulletins/approachprocedure-eng.php

Health Canada (2008h). Reconsideration Process. http://www.hc-sc. gc.ca/dhp-mps/prodnatur/legislation/docs/reconsid-eng.php

Health Canada (2009a). Assessment of Naturally Sourced Medicinal Ingredients found on Schedule F. http://www.hc-sc.gc.ca/dhpmps/prodnatur/bulletins/schedulef_annexef-2009-eng.php

Health Canada (2009b). Classification of Products at the FoodNatural Health Product Interface: Products in Food Formats. http://www.hc-sc.gc.ca/dhp-mps/prodnatur/legislation/docs/foodnhp-aliments-psn-guide-eng.php

Health Canada (2009c). Fact Sheet - The New Risk-Based Approach for Natural Health Products. http://www.hc-sc.gc.ca/dhp$\mathrm{mps} /$ pubs/natur/nhprr-rba_erpsn-gbr-eng.php

Health Canada (2009d). Natural Health Products Online Solution. http://www.hc-sc.gc.ca/dhp-mps/prodnatur/applications/onlineenligne/index-eng.php

Health Canada (2009e). Progress Report - Natural Health Products. http://www.hc-sc.gc.ca/dhp-mps/prodnatur/about-apropos/progrep-rap-etap-eng.php

Health Canada (2009f). The S.T.E.P.S plan. http://www.hc-sc.gc.ca/ dhp-mps/pubs/natur/nhprr-steps_erpsn-atsap-eng.php

Kwan D., Boon H.S., Hirschkorn K., Welsh S., Jurgens T., Eccott L., Heschuk S., Griener G.G. and Cohen-Kohler J.C. (2008). BMC Complement. Altern. Med., 8, 40.

Laliberté M.C., Normandeau M., Lord A., Lamarre D., Cantin I., Berbiche D., Corneille L., Prud'homme L. and Lalonde L. (2007). Use of over-the-counter medications and natural products in patients with moderate and severe chronic renal insufficiency. Am. J. Kidney Dis., 49(2), 245-56.

Laeeque H., Boon H., Kachan N., Cohen J.C. and D'Cruz J. (2006). The Canadian Natural Health Products (NHP) regulations: industry perceptions and compliance factors. BMC Health. Serv. Res., 6, 63.

Martyres S., Harwood M. and Nestmann E.R. (2008). Emerging policies and practices under the Canadian Natural Health Products Regulations. In: Bagchi D, editor. Nutraceutical and Functional Food Regulations in the United States and around the 
world. Burlinton: Elsevier Inc. p. 159-72.

Nestmann E.R., Harwood M. and Martyres S. (2006). An innovative model for regulating supplement products: Natural health products in Canada. Toxicol., 221(1), 50-9.

Putnam W., Lawson B., Frail D., Bower K., Archibald G., Conter H. and Mackillop J. (2006). Potential for drug interactions in seniors with osteoarthritis. Can. Fam. Physician, 52:340-1.

Seely D., Stempak D. and Baruchel S. (2007). A strategy for controlling potential interactions between natural health products and chemotherapy: a review in pediatric oncology. J. Pediatr. Hematol. Oncol., 29(1), 32-47.

Singh S.R. and Levine A.H.M. (2007). Potential interactions be- tween pharmaceuticals and natural health products in Canada. $J$. Clin. Pharmacol., 47, 249-58.

Whelan A.M., Jurgens T.M. and Lord L. (2008). Evaluating the quality of randomized controlled trials that examine the efficacy of natural health products: a systematic review of critical appraisal instruments. Evid. Based Complement. Alternat. Med., [Epub ahead of print].

Whelan A.M., Jurgens T.M., Bowles S.K. and Doyle H. (2009). Efficacy of natural health products in treating osteoporosis: what is the quality of internet patient advice? Ann. Pharmacother, 43(5), 899-907. 